\title{
2016 Nuclear Energy Voucher Pilot Program Final Summary
}

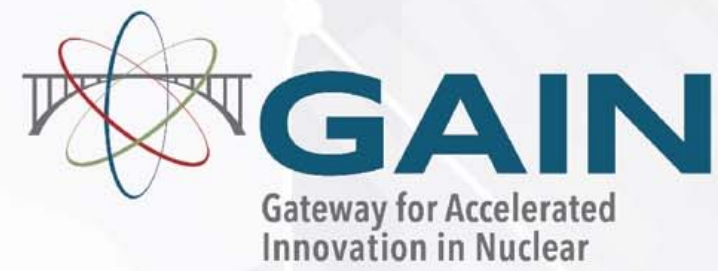




\section{Nuclear Energy Voucher Pilot Program Final Summary}

Prepared by:

John Jackson, GAIN Technical Interface

Approved by:

Rita Baranwal, GAIN Director 


\section{CONTENTS}

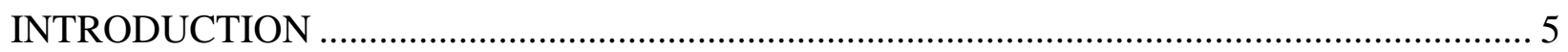

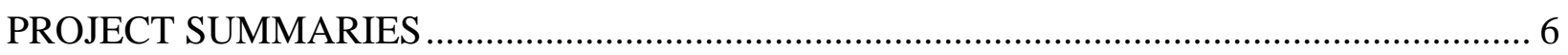

Creare, LLC - Investigation of Materials for Continuous Casting of Metallic Nuclear Fuel ..... 6

Columbia Basin Consulting Group, LLC - Lead-Bismuth Small Modular Reactor (SMR)

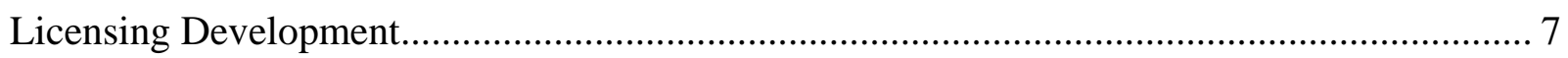

Terrestrial Energy USA, Ltd. - Verification of Molten-Salt Properties at High Temperatures .. 7

Transatomic Power Corporation - Optimization and Assessment of the Neutronics and Fuel

Cycle Performance of the Transatomic Power Molten Salt Reactor Design ............................... 8

Ceramic Tubular Products - Robust Silicon Carbide Cladding for LWR Application -

Corrosion and Irradiation Proof Test of Low Cost Innovations in the MITR.............................. 8

Oklo, Inc. - Legacy Metal Fuel Data Exploration for Commercial Scale-Up .............................. 9

CompRex, LLC - High Efficiency Heat Exchanger for High Temperature and High Pressure

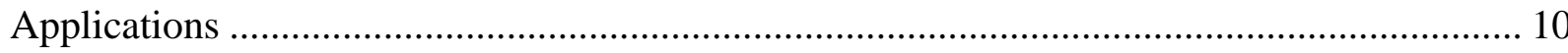

BgtL, LLC - High Efficiency and Low Cost Thermal Energy Storage System......................... 10

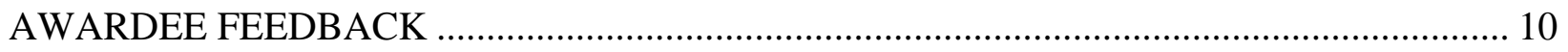

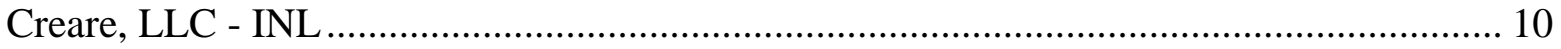

Columbia Basin Consulting Group, LLC - PNNL........................................................... 11

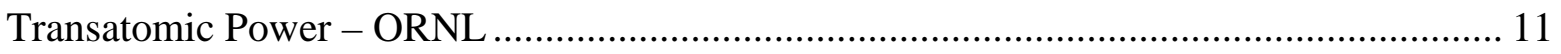

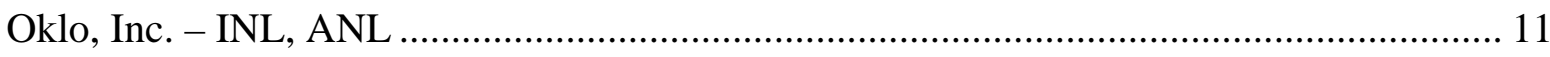

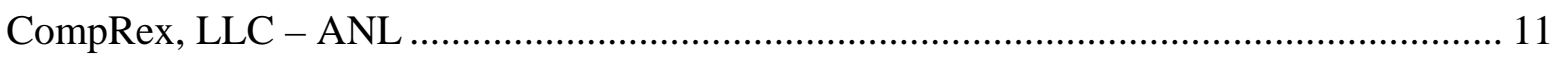

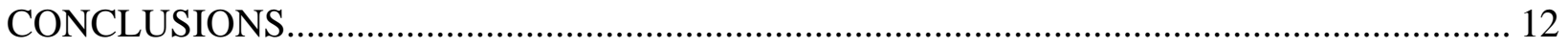

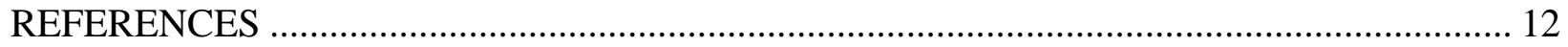

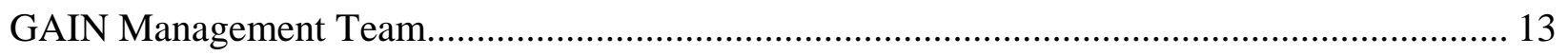




\section{ACRONYMS}

\begin{tabular}{|c|c|c|c|}
\hline ANL & Argonne National Laboratory & MITR & $\begin{array}{l}\text { Massachusetts Institute of } \\
\text { Technology Reactor }\end{array}$ \\
\hline \multirow[t]{2}{*}{ CBCG } & Columbia Basin Consulting & & \\
\hline & Group & MSR & molten salt reactor \\
\hline CRADA & $\begin{array}{l}\text { Cooperative Research and } \\
\text { Development Agreement }\end{array}$ & NRC & $\begin{array}{l}\text { U. S. Nuclear Regulatory } \\
\text { Commission }\end{array}$ \\
\hline DOE & Department of Energy & NSUF & Nuclear Science User Facilities \\
\hline FFTF & Fast Flux Test Facility & ORNL & Oak Ridge National Laboratory \\
\hline FSAR & Final Safety Analysis Report & PDC & Principal Design Criteria \\
\hline GAIN & $\begin{array}{l}\text { Gateway for Accelerated } \\
\text { Innovation in Nuclear }\end{array}$ & PNNL & $\begin{array}{l}\text { Pacific Northwest National } \\
\text { Laboratory }\end{array}$ \\
\hline INL & Idaho National Laboratory & TAP & Transatomic Power \\
\hline \multirow[t]{2}{*}{ MIT } & $\begin{array}{l}\text { Massachusetts Institute of } \\
\text { Technology }\end{array}$ & TEUSA & Terrestrial Energy USA \\
\hline & & U.S. & United States \\
\hline
\end{tabular}




\section{Nuclear Energy Voucher Pilot Program Final Summary}

\section{INTRODUCTION}

In March 2016, the United States (U.S.) Department of Energy (DOE) Office of Nuclear Energy (NE) Gateway for Accelerated Innovation in Nuclear (GAIN) initiative launched the NE Voucher pilot program for small businesses that develop advanced nuclear technologies. The program intent is to provide access to unique physical and intellectual capital that exists within the DOE national laboratory complex for private-sector developers of innovative nuclear energy technologies.

Vouchers allow recipients to have work performed on their behalf at select DOE laboratory facilities. The work is funded by DOE-NE and must be completed within approximately 12 months of the award date. Awards for the pilot had individual values of $\$ 50,000-300,000$, depending on the complexity of the task requested. The program requires a $20 \%$ cost share by voucher recipients. In addition to providing the technical assistance sought by the awardees, the 2016 pilot program award cycle showed that the program fosters relationships between these businesses and DOE laboratory staff, serving the GAIN mission to develop a private-public partnership framework that will enable accelerated commercialization of innovative concepts.

DOE-NE made a total of \$2M available for the inaugural voucher program. In total, twenty-nine proposals were received and eight (Table 1) were chosen for award based on several criteria, including technical quality, level of innovation, commercialization potential, and relevance to the DOE-NE mission. After the review process, cooperative agreements were finalized, and work on all eight voucher projects started in September 2016. Seven projects were completed by the end of September 2017 and the final project was completed in December 2017.

Table 1: 2016 NE voucher recipients.

\begin{tabular}{|l|l|l|}
\multicolumn{1}{|c}{$\begin{array}{c}\text { 2016 NE Voucher } \\
\text { Recipients }\end{array}$} & \multicolumn{1}{c|}{ Proposal } & Partner Facility \\
\hline $\begin{array}{l}\text { Creare, LLC } \\
\text { Hanover, NH }\end{array}$ & $\begin{array}{l}\text { Investigation of Materials for Continuous Casting of } \\
\text { Metallic Nuclear Fuel }\end{array}$ & $\begin{array}{c}\text { Idaho National } \\
\text { Laboratory }\end{array}$ \\
\hline $\begin{array}{l}\text { Columbia Basin Consulting } \\
\text { Group, LLC } \\
\text { Kennewick, WA }\end{array}$ & $\begin{array}{l}\text { Lead-Bismuth Small Modular Reactor (SMR) } \\
\text { Licensing Development }\end{array}$ & $\begin{array}{c}\text { Pacific Northwest } \\
\text { National Laboratory }\end{array}$ \\
\hline $\begin{array}{l}\text { Terrestrial Energy USA, Ltd. } \\
\text { New York, NY }\end{array}$ & $\begin{array}{l}\text { Verification of Molten-Salt Properties at High } \\
\text { Temperatures }\end{array}$ & $\begin{array}{c}\text { Argonne National } \\
\text { Laboratory }\end{array}$ \\
\hline
\end{tabular}




\begin{tabular}{|c|c|c|}
\hline $\begin{array}{l}2016 \text { NE Voucher } \\
\text { Recipients }\end{array}$ & Proposal & Partner Facility \\
\hline $\begin{array}{l}\text { Transatomic Power } \\
\text { Corporation } \\
\text { Cambridge, MA }\end{array}$ & $\begin{array}{l}\text { Optimization and Assessment of the Neutronics } \\
\text { and Fuel Cycle Performance of the Transatomic } \\
\text { Power Molten Salt Reactor Design }\end{array}$ & $\begin{array}{l}\text { Oak Ridge National } \\
\text { Laboratory }\end{array}$ \\
\hline $\begin{array}{l}\text { Ceramic Tubular Products } \\
\text { Rockville, MD }\end{array}$ & $\begin{array}{l}\text { Robust Silicon Carbide Cladding for LWR } \\
\text { Application - Corrosion and Irradiation Proof Test } \\
\text { of Low Cost Innovations in the Massachusetts } \\
\text { Institute of Technology (MIT) Reactor (MITR) }\end{array}$ & $\begin{array}{l}\text { Massachusetts Institute } \\
\text { of Technology }\end{array}$ \\
\hline $\begin{array}{l}\text { Oklo, Inc. } \\
\text { Sunnyvale, CA }\end{array}$ & $\begin{array}{l}\text { Legacy Metal Fuel Data Exploration for } \\
\text { Commercial Scale-Up }\end{array}$ & $\begin{array}{l}\text { Argonne National } \\
\text { Laboratory/ldaho } \\
\text { National Laboratory }\end{array}$ \\
\hline $\begin{array}{l}\text { CompRex, LLC } \\
\text { De Pere, WI }\end{array}$ & $\begin{array}{l}\text { High Efficiency Heat Exchanger for High } \\
\text { Temperature and High Pressure Applications }\end{array}$ & $\begin{array}{l}\text { Argonne National } \\
\text { Laboratory }\end{array}$ \\
\hline $\begin{array}{l}\text { BgtL, LLC } \\
\text { Laramie, WY }\end{array}$ & $\begin{array}{l}\text { High efficiency and low cost thermal energy } \\
\text { storage system }\end{array}$ & $\begin{array}{l}\text { Argonne National } \\
\text { Laboratory }\end{array}$ \\
\hline
\end{tabular}

\section{PROJECT SUMMARIES}

Each voucher pilot project awardee was asked to provide a summary of their experience both at roughly the mid-point of their project and at the conclusion. These are consolidated in the following project outcomes.

\section{Creare, LLC - Investigation of Materials for Continuous Casting of Metallic Nuclear Fuel}

Creare, LLC, worked with staff at the Idaho National Laboratory (INL) to develop initial concepts for coating samples to be used in testing a continuous casting process that will help to reduce costs of fuel pin production compared with existing injection casting methods. Candidate multi-layer coatings for use with a graphite substrate were identified and initial casting trials conducted through this voucher provided valuable supporting data for hypotheses on coatings and treatments for this system. The work also provided experience with coating of high temperature alloys ( $\mathrm{Cu}-\mathrm{Ni}$ in this case) as a progression from previous experience with lower temperature alloys. The results of this voucher will be used to plan the next evolution of coating technology, which is a necessary step toward commercialization of the process. Unique capability provided by INL included use of a mechanically reliable crucible that maintained purity of the fuel material during the casting process as well as the expertise offered by INL in assessing material behavior in nuclear fuel fabrication systems. 


\section{GAIN}

Columbia Basin Consulting Group, LLC - Lead-Bismuth Small Modular Reactor (SMR) Licensing Development

Staff at Pacific Northwest National Laboratory (PNNL) performed reviews (based on typical licensing evaluations) of a Columbia Basin Consulting Group (CBCG) lead bismuth (Pb-Bi) reactor design concept against (1) Chapter 15 of the Final Safety Analysis Report (FSAR) ${ }^{1}$ for the Fast Flux Test Facility (FFTF) focused on design basis accidents, (2) Appendix A of the FFTF FSAR, which considers beyond design basis accidents, and (3) the 64 principal design criteria (PDCs) proposed in INL/EXT-14-31179, “Guidance for Developing Principal Design Criteria for Advanced (Non-Light Water) Reactors," ${ }^{2}$ and incorporated the results into the draft U.S. Nuclear Regulatory Commission (NRC) Regulatory Guide DG-1330. ${ }^{3}$ The results of these reviews are expected to help the CBCG develop an initial licensing position for their $\mathrm{Pb}-\mathrm{Bi}$ reactor plant design. A review against the "NRC Gap Analysis for Advanced Reactor Regulatory Infrastructure" for Chapter 15 was finalized. Ultimately, the project served to identify potential gaps and required adjustments to Chapter 15 and the sodium fast reactor PDCs to allow licensing review of the $\mathrm{Pb}-\mathrm{Bi}$ reactor design.

This effort was a fundamental building block that allows CBCG to continue with a reasonable expectation of investment funding and programmatic success. The work addressed the acceptance of the $\mathrm{Pb}-\mathrm{Bi}$ reactor technology for licensing by the NRC. The NE Voucher pilot program collaboration yielded a highly credible assessment of the potential "show-stopper" concerns with licensing this technology in the U.S.

\section{Terrestrial Energy USA, Ltd. - Verification of Molten-Salt Properties at High Temperatures}

On behalf of Terrestrial Energy USA (TEUSA), Ltd., staff at Argonne National Laboratory (ANL) procured, prepared, and characterized fluoride salt compositions relevant to the TEUSA molten salt reactor (MSR) design. After demonstrating the suitability of these fluoride salt compositions for use in heat capacity determination, voucher work was focused on measurement and assessment of the heat capacity of these salts for delivery to TEUSA. After the heat capacity measurements were completed, ANL verified the solubility of lanthanide fission products in the fluoride-based fuel salt at conditions relevant to the molten salt reactor design and verify behavior models.

The NE voucher pilot program allowed TEUSA to obtain actual thermo-physical properties of fuel salts using modern experimental methods, rather than close approximations based on historical data. Access to ANL infrastructure and expertise allowed TEUSA to overcome a critical roadblock to success in commercialization of the Integral Molten Salt Reactor (IMSR ${ }^{\circledR}$ ) by allowing the design to be refined and optimized with respect to the fuel salt properties. 


\section{GAIN}

Transatomic Power Corporation - Optimization and Assessment of the Neutronics and Fuel Cycle Performance of the Transatomic Power Molten Salt Reactor Design

Oak Ridge National Laboratory (ORNL) provided a neutronic and fuel cycle analysis of the Transatomic Power Corporation (TAP) MSR core design, which uses configurable zirconium hydride moderator rod assemblies to shift the neutron spectrum in the core from primarily epithermal at beginning of life to thermal at end of life. The work implemented continuousenergy Monte Carlo transport and depletion tools in ChemTriton to provide full-core threedimensional simulation and modeling. Simulations with these tools showed agreement with TAP-calculated performance metrics for core lifetime, discharge burnup, and salt volume fraction, verifying the viability of reducing actinide waste production with this design concept.

This voucher project, using ORNL-developed tools to independently assess the TAP MSR concept, highlighted the flexibility of ORNL's tools in addressing specific designs. This independent verification is crucially important for TAP as the company moves towards the next phases of their design process, and is also very helpful when discussing their work with potential investors and other collaborators. Additional analyses of mass feed rates and enrichments, isotopic removals, tritium generation, core power distribution, core vessel helium generation, moderator rod heat deposition, and reactivity coefficients provided additional critical-path information to guide the next stages of TAP's reactor design development.

The TAP voucher work with ORNL was captured in three publically available documents; ${ }^{4,5,6}$ two technical memoranda available through OSTI, and a publication co-authored by ORNL staff and TAP staff:

\section{Ceramic Tubular Products - Robust Silicon Carbide Cladding for LWR Application - Corrosion and Irradiation Proof Test of Low Cost Innovations in the MITR}

A Nuclear Science User Facilities (NSUF) partner facility, the MITR received newly formulated silicon carbide ( $\mathrm{SiC}$ ) TRIPLEX cladding test specimens from Ceramic Tubular Products (CTP) and loaded the samples into irradiation test capsules. In January 2017, MIT placed the irradiation test capsules into their test reactor for two full cycles of irradiation. After the specimens were removed from the test reactor in June 2017, physical property measurements of the test specimens were performed to ascertain performance improvements for this economically superior (compared to previous TRIPLEX versions) cladding coating.

Key results from the testing and examination include the following: 
- Weight loss from the uncoated samples was higher than the loss from previous experiments containing a high temperature $\mathrm{SiC}$ chemical vapor deposition environmental barrier coating, and exceed that which would be acceptable in commercial service.

- Weight loss from the zircon-coated specimens exceeded what would be acceptable for commercial service.

- Subject SiC fibers showed about the same amount of corrosion as those with the more traditional high Nicalon-S fibers indicating either could be use in future commercial applications.

The key physical properties measurements obtained by MIT on behalf of CTP represent a valuable data set that will be used by CTP to further perfect the TRIPLEX clad material and work toward commercial acceptance.

\section{Oklo, Inc. - Legacy Metal Fuel Data Exploration for Commercial Scale-Up}

Researchers at both INL and ANL assisted Oklo, Inc. in compiling and assessing information about legacy metal fuel data and commercial fabrication, which is of interest to the larger reactor development community. INL performed BISON analyses to provide insights on an innovative, but unorthodox, metallic fuel design of interest to Oklo and developed a concept for fabrication of the Oklo fuel element. As a result, Oklo has submitted an application for its own BISON license; its key staff members subsequently received training at INL. ANL reviewed existing fuel irradiation data and identified which parts of this data were relevant to the Oklo fuel design. INL and ANL provided technical support by participating in a pre-application meeting between Oklo and NRC staff, providing technical support.

In addition to the BISON modeling efforts, INL was able to successfully fabricate a series of metallic fuel prototypes to Oklo's specifications that were partially informed by the modeling efforts. This fabrication effort confirmed feasibility of the Oklo fuel prototype and provides them with necessary experience to progress with overall design of their reactor.

By working with the technical experts at INL and ANL through the initial GAIN program, Oklo was able to establish a working relationship and an increased understanding of the labs' capabilities that directly led to other collaborations. It is important to note that although the work performed under the GAIN initiative was specific to the Oklo reactor design in certain aspects, much of the work done helped develop processes and lessons learned that will help the broader nuclear community, and improve accessibility to legacy data for the entire nuclear community.

The information and data from these efforts helped Oklo with both its licensing and manufacturing activities and helps to accelerate the overall commercialization effort for their reactor concept. 


\section{GAIN}

\section{CompRex, LLC - High Efficiency Heat Exchanger for High Temperature and}

\section{High Pressure Applications}

ANL researchers performed an initial review of a CompRex, LLC's innovative high-efficiency, compact, diffusion bonded heat exchanger concept, which is different from printed circuit heat exchangers. A new thermal hydraulic model, which was used to optimize heat exchange capacity and pressure drop performance of the heat exchanger, was developed by ANL with direction from CompRex. The model confirmed the targeted benefits of the CompRex design and samples of both the optimized and non-optimized heat exchangers were subsequently fabricated for comparison. The collaborative work between CompRex and ANL is continuing in order to obtain heat exchanger test data and evaluate improvement.

The initial simulation results from the model confirmed the benefits from the new design, which will support CompRex in further commercialization of the design.

\section{BgtL, LLC - High Efficiency and Low Cost Thermal Energy Storage System}

ANL also worked with staff at BgtL, LLC to assess the utility of a new, innovative aluminum alloy thermal energy storage system for use with different energy systems, including a 150MWth sodium fast reactor, a solar power tower solar energy system, windmills, and photovoltaic solar energy systems. This assessment confirmed the technical viability of the concept and identified photovoltaic solar energy as the best near-term market for the new thermal energy storage system. The voucher work also resulted in identification of a potential corrosion issue and involved formulation and testing of a solution to this problem involving use of coatings.

\section{AWARDEE FEEDBACK}

General feedback on the voucher and associated processes, both positive and negative was solicited from all eight awardees. The following sections list capture this feedback where provided.

\section{Creare, LLC - INL}

- The overall program organization was a little opaque to us, but that did not hinder the technical work.

- Communications between GAIN, INL and Creare were a bit awkward, which is probably typical for a pilot program. There was often a lag in communication and understanding as to where we, collectively were in the process among DOE GAIN, INL and Creare counterparts, but overall, the system worked.

- INL was very professional and efficient at establishing a Cooperative Research and Development Agreement (CRADA) with Creare. 


\section{Columbia Basin Consulting Group, LLC - PNNL}

- The GAIN Program was the answer that CBCG needed for sufficient resources to address critical issues. GAIN provided CBCG access to the nuclear technology and regulatory expertise of our GAIN partner, PNNL. Without the GAIN program, such resources and research tasks would be financially out-of-reach to our firm.

- Although the completion of the application scopes is the most tangible benefit to participants, CBCG has benefited in many avenues from our association with PNNL and the opportunities the GAIN program has afforded in cross-sharing with other GAIN program participants. PNNL has provided insights and guidance from a reservoir of experience and expertise within both the DOE and NRC and has assisted CBCG in awareness of the many activities within various government sources that would not be visible to CBCG due to the high financial investment requirements of such a knowledge network.

\section{Transatomic Power - ORNL}

- At the proposal stage, there was a focus on keeping the work scope manageable, and setting clear expectations for deliverables. This emphasis on concrete, commercialization-driven deliverables helped keep the work focused and fast-paced.

- The standardized contracting (i.e., following a standard CRADA agreement) greatly sped up the contracting process, and I really appreciated the straightforwardness of this process. The IP terms in this agreement were very reasonable from TAP's perspective.

Oklo, Inc. - INL, ANL

- The CRADA timelines were longer than anticipated. These timelines seem to vary by lab, so hopefully successful lessons learned can be shared across labs.

- There were some missed opportunities to better communicate resource planning between the labs that could have streamlined workflow.

\section{CompRex, LLC - ANL}

- Through this program, we initiated a great working relationship with ANL. The team at ANL is very knowledgeable and provided expert assistance. We now have a better understanding of ANL's capabilities and will try to seek more collaborations in the future. 


\section{CONCLUSIONS}

The NE Voucher pilot program successfully met the following objectives:

- Facilitated access to critical national laboratory expertise and infrastructure needed by the small business companies to advance their innovative ideas closer to commercialization.

- Provided insights and technology guidance to the small businesses based on the experience and expertise within DOE's national laboratories.

- Implemented a standardized contracting process that greatly decreased time spent on getting contracts in place.

- Increased understanding of the national laboratories' capabilities that can be utilized in the future on collaboration efforts with private industry.

- Fostered relationships between national laboratories and the private sector to encourage future collaborative efforts.

The 2016 NE Voucher pilot program is considered a success and was transitioned to a continuing program in 2017 with award of 14 vouchers with a total, cumulative value of over $\$ 4$ million. Of the 14 awardees, four were repeat awardees from the 2016 pilot. All pilot awardees report an overall positive experience with the voucher program.

\section{REFERENCES}

1. Westinghouse, 1975, Final Safety Analysis Report for the Fast Flux Test Facility, Westinghouse Hanford Company (December 1975).

2. INL/EXT-14-31179, Guidance for Developing Principal Design Criteria for Advanced (Non-Light Water) Reactors, Idaho National Laboratory.

3. DG-1330, "Guidance for Developing Principal Design Criteria for Non-Light Water Reactors,” U.S. Nuclear Regulatory Commission.

4. ORNL/TM-2016/742, Two-Dimensional Neutronic and Fuel Cycle Analysis of the Transatomic Power Molten Salt Reactor. January 2017.

5. ORNL/TM-2017/475, Assessment of the Neutronic and Fuel Cycle Performance of the Transatomic Power Molten Salt Reactor Design. September 2017.

6. ORNL, Fuel Cycle and Neutronic Performance of a Spectral Shift Molten Salt Reactor Design. Submitted to Annals of Nuclear Energy, December 2017. 


\section{GAIN Management Team}

Rita Baranwal, GAIN Director

Andrew Worrall, GAIN Deputy

Lori Braase, GAIN Coordinator

John Jackson, GAIN Technical Interface

Hussein Khalil, GAIN Integration Working Group Chair

Prepared for the U.S. Department of Energy

Office of Nuclear Energy Under DOE Idaho Operations Office

Contract DE-AC07-05ID14517 